advances of science since the ninth edition was prepared, in so far as they come within the purview of the present volume. Whether considered as one volume of a supplement to the ninth edition or as a statement of the position of many scientific subjects, the work is a worthy addition to our national literature.

\section{PRACTICAL PHYSIOLOGY.}

Directions for Class Work in Practical Physiology. Elementary Physiology of Muscle and Nerve and of the Vascular and Nervous Systems. By E. A. Schäfer, LL.D., F.R.S. Pp. 76. (London: Longmans, Green and Co., Igor.) Price 3 s. net.

THE contents of this book are well-nigh sufficiently indicated by its subsidiary title, and it is inconceivable that in dealing with the elementary aspects of the subjects named its distinguished author could go wrong. He informs us that his directions are based upon an experience of many years in University College, London, and that they deal "only with such elementary exercises as can readily be worked out by even a large class."

There are twelve chapters in all, and the most distinctive feature of the book is the manner in which the student, having been given concise instructions as to the nature and mode of utilisation of apparatus, and of preparation of the organic object to be studied, is left to "notice" or observe for himself the nature of the effect of this or that operation. A most wholesome procedurea method of the kind which must be always begotten of a lengthy teaching experience such as the author proclaims.

Of the twelve chapters, the first opens with a description of the "voltaic element" and of the Daniell cell, the rationale of the replacement of the former by the latter being clearly explained. The Grove and Leclanché cells, with the chief types of the latter, are in turn considered; and, with adequate descriptions of electrodes, keys, rheochords, the induction coil and their uses, and a section on unipolar induction, the chapter closes. Chapters ii. and iii. are devoted to nervemuscle preparations, the sartorius being utilised for the demonstration of the independent irritability of muscle and nerve, and the hyoglossus for that of the "latent period." The effects of heat and cold, of fatigue, the action of curari and veratrin, are in due course considered and clearly set forth; and in chapters v., vi. and vii. the effects of successive stimulation, leading up to tetanus and the muscle sound, the rate of the nervous impulse, the effects of $\mathrm{CO}_{2}$ and the "electrotonus" phenomenon, are simply described, Ritter's and Pfluger's laws being incidentally laid down.

Chapter viii. deals with secondary contraction and the use of the capillary electrometer and galvanometer. The two chapters which follow are devoted to the heart, cardiac nerves, and the use of the plethysmograph; and the two which conclude the work deal with the chief vascular and respiratory mechanisms in man, with reflex action and its time limitations, as determinable by the use of the Wallerian lever apparatus.

There are in all forty-five simple text-illustrations, thirty-eight of apparatus and seven of dissections of the common frog. The book is well worthy its aim, and Prof. Schäfer, clearly of a mind to give the elementary NO. I 700 , VOL. 667 student little and good, has done that functionary a great service.

There are, in addition to the seventy-six printed pages, twenty-six which are blank; but whether, according to the bookbinder's custom, these are intended to give stability to an otherwise thin volume, or whether they are for the convenience of the student in making annotations, we are not informed. As matters now progress, however, in electrophysiology, it would seem that ere long one or two of these blank pages may be destined to bear a thirteenth chapter, since the Eastern mind, coming fresh and untrammelled to the work, is showing us that under a mechanical stimulus phenomena of electrical response akin to those until recently demonstrated only for the higher animals and the sensitive plants, appear to be at least also obtainable from vegetable organisms at large - a result which points to the conclusion that in these well-known phenomena we are dealing with a fundamental property of protoplasm, and calls for immediate investigation of the unicellular organisms, in the study of which the clue to all that is physiological has ever to be sought.

\section{OUR BOOK SHELF.}

The Elements of Physical Chemistry. By J. Livingston R. Morgan, Ph.D. Second edition. Pp. $x+352$. (New York: Wiley and Son; London: Chapman and Hall, Ltd., 1902.) Price 2 dollars.

To write a book the object of which is to present the elements of the entire subject of physical chemistry, together with the important and but little known applications of it to the other branches of chemistry, within the scope of 322 small pages is by no means an easy task. The author has, however, succeeded in presenting within these limits a very readable account of the subject.

To the reader familiar with the works on physical chemistry and electrochemistry published by German authors during the last ten years, a close likeness between these and the present volume is at once apparent. The author, as a matter of fact, in his preface states that no claims of originality are made for the major portion of the text.

It is doubtful whether a text-book which is obviously intended for the use of comparatively elementary chemical students should be so replete with mathematical formulæ. For a beginner, a more descriptive method of treatment of the subject would have been, in the opinion of the reviewer, more satisfactory.

The subject-matter is divided into ten chapters, the first being devoted to introductory remarks on the subject of energy and methods of determining atomic weights; then follow sections on the gaseous, liquid and solid states, solution, thermochenistry, chemical change, phases and electrochemistry, the last chapter containing a series of 156 problems bearing upon the subject-matter of the text. This last chapter is a most welcome innovation. For the beginner, the very numerous and abstract formulæe of physical chemistry have but a vague significance; only when these formulæ have been applied to concrete cases do they become properly understood by the student. Ample scope for exercise in the application of these formulæ is provided by the last chapter, although perhaps in a few cases the problems are not very happily chosen.

Thermochemistry and the phase rule are treated of in a superficial manner, only five pages being devoted to the consideration of the latter. In a future edition it is hoped that the author will see fit to deal with the important work which has been done on transition tem- 